\title{
Lower Body Lymphedema in Patients with Gynecologic Cancer
}

\author{
NICOLETTA BIGLIA, VALENTINA ZANFAGNIN, ALBERTO DANIELE, \\ ELISABETTA ROBBA and VALENTINA E. BOUNOUS \\ Obstetrics and Gynaecology Unit, Umberto I Hospital, \\ Department of Surgical Sciences, School of Medicine, University of Turin, Turin, Italy
}

\begin{abstract}
Lower body lymphedema is a chronic condition and a significant cause of morbidity following treatment of gynecologic cancer that strongly impacts patients' quality of life (QoL). Most studies on secondary lymphedema have been performed on the upper limb after breast cancer treatment and much less is known about lower body lymphedema after gynecologic malignancies. This review focuses on secondary lymphedema due to gynecologic cancer treatment, analyzing its incidence in the different types of gynecologic cancer, diagnosis, risk factors, impact on QoL and treatment. A systematic search of Medline has been performed to track the studies evaluating lower body lymphedema after treatment for endometrial, ovarian, cervical and vulvar cancer. Unfortunately, there is no consensus about a uniform evaluation and, as a consequence, the reported incidence is broadly different among the studies. Standardization in lymphedema evaluation is required to better compare the outcome of different types of treatment.
\end{abstract}

Lower body lymphedema is a chronic condition affecting women treated for gynecologic malignancies. It can be asymptomatic or associated with the feeling of heaviness, erythema and pain, often requiring lifelong treatment and psychosocial support (1).

Lymphedema is the result of lymphatic system insufficiency and impaired lymph transport. The core issue is a low output failure of the lymph vascular system, leading

This article is freely accessible online.

Correspondence to: Ass. Prof. Nicoletta Biglia, Obstetrics and Gynaecology Unit, Umberto I Hospital, Department of Surgical Sciences, School of Medicine, University of Turin, Largo Turati 62, 10128 Turin, Italy. Tel: +39011 5082684, Fax: +39011 5082683, e-mail: nicoletta.biglia@unito.it

Key Words: Lymphedema, ovarian cancer, vulvar cancer, endometrial cancer, cervical cancer, quality of life, review. to a reduction of lymphatic transport below the capacity needed to handle the load of microvascular filtrate.

Doderlein described the lymphatic drainage system of the female genital tract in three lymphatic basins: the first includes drainage from the vulva and the lower third of the vagina up to the inguinofemoral nodes; the second involves the drainage from the upper vagina and the cervix to the pelvic wall vessels and the third the drainage from the uterine corpus and the ovaries to the paraaortic and paracaval lymph nodes located between the renal vessels and the inferior mesenteric artery (2). Special attention merits the most distal external iliac nodes, also called circumflex iliac lymph nodes, located between the deep circumflex iliac vein and the femoral canal.

Lymphedema related to cancer treatment arises from the anatomical obliteration, such as after radical operative dissection, irradiation, or from repeated lymphangitis ending in lymphangiosclerosis (3).

Injury to the pelvic lymphatic system affects its capacity to absorb excess fluid and decreases membrane permeability allowing escape of fluids, proteins and cells into extracellular spaces with consequent swelling. Persistent edema can determine fibrosis due to long-term parenchymal and stromal elements proliferation and excessive deposition of extracellular matrix, whereas protein pooling provides a medium for cellulitis and lymphangitis $(3,4)$.

Lower Limb Lymphedema (LLL) is the most frequent expression of lower body lymphedema and deserves the vast majority of the papers on the subject. Gynecologic cancer treatment is also associated with other sequelae involving the lymphatic system: lymphocele, reported in around 20-30\% of patients and mostly being an incidental finding during post-operative imaging (5) and a specific and rare subtype of lymphedema involving genitals and mons pubis, that may occur after gynecologic cancer treatment, mainly vulvar, but that is mostly known as a complication of severe obesity and of surgery and radiotherapy in males.

Lymphadenectomy is the surgical procedure more frequently associated with LLL. 
The therapeutic benefit of lymphadenectomy is controversial, and the complications of this procedure must be cautiously evaluated. Lymphadenectomy is mainly performed for staging purposes and survival benefit is not demonstrated (6-8). The introduction of sentinel node (SLN) biopsy for selected cases of endometrial, cervical and vulvar cancer is promising since it minimizes the risk of lymphedema, it detects key nodes even when they are in atypical locations and allows detecting small metastasis (9).

Pelvic and para-aortic lymphadenectomy are usually performed through laparotomy. The emerging laparoscopic approach aims at reducing surgical morbidities such as postoperative pain, blood loss and hospital stay. Laparoscopic lymphadenectomy is a safe and feasible procedure; however, it is not free of complications (10) and there is no consensus about its ability to reduce the risk of lymphedema, even though in a recent paper the patients who underwent an open surgical procedure experienced a higher incidence of lymphedema than those who were treated with endoscopic surgery (11).

The diagnosis of lymphedema is challenging: signs and symptoms are often unrecognized, and limb lymphedema can be bilateral, thus preventing the comparison with an unaffected leg; furthermore, adiposity (especially in obese patients) might mask the condition. Last, but not least, poor knowledge exists among both healthcare professionals and patients about lymphedema and its management.

This review will focus on secondary lymphedema due to gynecologic cancer treatment.

\section{Search Strategy and Selection Criteria}

We conducted a systematic search of Medline using the relevant medical subject heading search (MESH) with the following keywords: "lymphedema", "genital neoplasm, female", "ovarian neoplasms", "vulvar neoplasms", "endometrial neoplasms", "uterine cervical neoplasms", "surgery", "radiotherapy", "quality of life".

Only the publications written in English were considered and original papers selected for inclusion were independently reviewed by three Authors (VB, VZ and AD).

No systematic reviews or concluded randomized controlled trials (RCTs) were found; the majority of the studies were primary research studies.

\section{Classification}

The more frequently used system to describe lymphedema of the limbs is the International Society of Lymphology 4-stage classification:

- Stage 0 (or Ia) which refers to a latent or sub-clinical condition where swelling is not yet evident despite impaired lymph transport, subtle changes in tissue fluid/composition, and changes in subjective symptoms.
- Stage I represents an early accumulation of fluid relatively high in protein content which subsides with limb elevation. - Stage II means that limb elevation alone rarely reduces tissue swelling and pitting is evident.

- Stage III encompasses lymphostatic elephantiasis where pitting can be absent and skin changes such as acanthosis, further deposition of fat and fibrosis, and warty overgrowths have developed (12).

\section{Diagnosis}

Lymphedema diagnosis after gynecological cancer treatment is often difficult since signs and symptoms can be unrecognized, leading to inadequate referrals and treatment delay. In most of the cases, lymphedema is diagnosed within the first year after treatment $(4,13,14)$.

The best method for LLL diagnosis has not yet been established. However, the most accurate diagnostic method that has been reported until now is the physical examination performed by an experienced lymphedema specialist (15).

Objective evaluation of LLL is mostly performed by the comparative circumferential measurement, in which one limb is compared with the opposite in four specific points: metatarsal-phalangeal joints, $2 \mathrm{~cm}$ up to the medial malleolus, ten above and below of the patella. A unique definition is lacking, but a circumferential difference of 2 to $2.5 \mathrm{~cm}$ on several levels between the two legs seems consensual to make a diagnosis of lymphedema (16).

Unfortunately, LLL is often bilateral and proximal, since it is due to para-aortic, bilateral pelvic or inguinal lymph nodes dissection or irradiation. Thus, differently from what happens for breast cancer, there is not always a reference limb for diagnosis. Moreover, secondary lymphedema often begins at thigh level descending towards the calf and the foot, which can remain unaffected, in particular for a patient with cervical cancer (13). The onset of lymphedema at distal levels (foot and ankle) with an upward extension is not frequent and allows an easier diagnosis. In the case of LLL localized to feet, a specific diagnostic test consists in pinching the skin between the second and third fingers or between the toes; lymphedema is diagnosed if the pinched skin does not fold up (Stemmer's sign) (3).

Limb volume can also be evaluated by different methods. In clinical trials, the water displacement method is widely used, which detects volume changes of less than $1 \%$; a volume difference of $200 \mathrm{ml}$ between the two limbs is the cut-off point to diagnose lymphedema. This method is really precise but difficult to use in routine practice. Optoelectronic volumetry uses infrared light to scan limbs and estimate the volume converting cross-sectional measurements at multiple intervals. At last, the volume can be calculated with the truncated cone formula: from the ankle, marks are fixed every $4 \mathrm{~cm}$ up to hip; the circumference measurements of 
each cylinder are converted to volume using a specific algorithm (17).

Newer technologies including three-dimensional magnetic resonance imaging (MRI) (18), lymphoscintigraphy, computerized tomography (CT), ultrasound (19) and bioelectrical impedance analysis are reserved for patients with bilateral lymphedema without a definitive diagnosis or in cases where a lymphatic obstruction is suspected for malignancy. Lymphoscintigraphy is not commonly used, due to the lack of standardized protocol in performing the test. Ultrasound is useful to exclude other etiologies like deep venous thrombosis, venous insufficiency and can also help in identifying tissue changes and masses that might be the cause of lymphatic compression. CT and MRI can investigate soft tissue edema with a good sensitivity and specificity, but they are relatively expensive (3).

With regard to subjective evaluation, general scales poorly focus on LLL: the most widely used tool to evaluate QoL in cancer patients is the EORTC QLQ-C30 (20).

A specific scale for the evaluation of LLL in gynecologic cancer patients is the Gynecologic Cancer Lymphedema Questionnaire (GCLQ) (21) which is a 20 items selfreporting questionnaire analyzing physical functioning (weakness and limited movement), numbness, swelling, infections, heaviness and aching in the previous 4 weeks.

Unfortunately, the vast majority of studies reporting the incidence of LLL after treatment of gynecological cancer do not use both objective and subjective evaluation tools or do not specify the evaluation method used.

\section{Incidence}

The reported incidence of lower body lymphedema following gynecologic cancer treatment ranges from 0 to $70 \%(22,23)$. Since no consensus exists on a uniform diagnostic evaluation, the incidence is broadly different among the studies. This huge difference may also depend on the nature of cancer, the type of treatment, the surgical radicality, the differences in measurement techniques and the kind of assessment used (subjective complaints or objective clinical diagnosis).

Endometrial cancer. Endometrial cancer (EC) is the most common gynecologic malignancy in developed countries, and its incidence is increasing, likely because of aging populations and rise in obesity (24). Since most cases are diagnosed at an early stage of the disease and the prognosis is generally favorable, these patients frequently live long enough to develop late side-effects associated with treatments, among which lymphedema is one of the most debilitating. Retrospective studies have investigated its incidence in EC using both charts revision methods (where the condition was reported either by the physician or the patient) and patients' responses to questionnaires. The incidence varies from 1.2-47\%, depending on the assessment method $(25,26)$. Several risk factors for the development of lymphedema in EC have been investigated, among which pelvic and para-aortic lymphadenectomy (27), postoperative radiotherapy and obesity appear to play a major role.

The higher risk of lymphedema in patients in whom a complete pelvic and or para-aortic lymphadenectomy was performed is reported by a recent meta- analysis (relative risk 8.39, 95\% $\mathrm{CI}=4.06-17.33$ when compared to no lymphadenectomy) (28).

Surgery has a pivotal role in the initial treatment of EC. The standard surgical approach is a total hysterectomy with bilateral salpingo-oophorectomy without vaginal cuff, performed preferably by minimally invasive techniques (laparoscopy or robotic-assisted surgery). Lymphadenectomy is part of the FIGO (International Federation of Gynecology and Obstetrics) surgical staging system since the nodal status determines prognosis and addresses adjuvant therapies. However, the role and the extent of lymph node assessment is controversial, particularly in early stage disease where the risk of overtreatment is not negligible.

Currently, a complete surgical staging is recommended in patients with high-risk tumors (grade 3 with myometrial invasion $>50 \%$ ), while it can be considered for staging purposes in patients with intermediate risk (myometrial invasion $>50 \%$ or grade 3 with myometrial invasion $<50 \%$ ). In low-risk tumors (grade 1 or 2 with myometrial invasion $<50 \%$ ), lymphadenectomy is not recommended. These recommendations are supported by the results of two RCTs that showed no impact on survival when performing lymphadenectomy in early-stage disease $(6,7)$; on the contrary retrospective cohort studies showed opposite results (29).

Low-grade tumors occur in relatively younger and obese patients, while high-grade tumors are seen in an older and non-obese population set. Since obesity is a proven risk factor for the development of lymphedema, avoiding lymphadenectomy in these subsets of patients is of the utmost importance for reducing the burden of $\operatorname{LLL}(30,31)$.

Other lymphadenectomy-related factors that have been considered are the number of lymph nodes removed or the extent of the lymphadenectomy. The association between each of these factors and the development of lymphedema is still controversial, notably because the number of lymph nodes removed varies greatly among the studies $(26,32,33)$.

A cut-off number of lymph nodes above which lymphedema occurs has not been clearly defined. Regarding the distal limit of lymphadenectomy, it has been shown that preserving the circumflex iliac lymph node is a potential strategy to reduce the risk of developing LLL (34).

In this scenario, the SLN mapping technique has the potential advantage to reduce the disruption of the lymphatic channels when compared with more extensive lymphadenectomy. It has recently gained credibility as a 
valuable staging technique, with detection rates of $81 \%$ $(95 \% \mathrm{CI}=77-84)$ and sensitivity of $96 \%(95 \% \mathrm{CI}=92-98)$, as reported by a recent meta-analysis (35). Data on the lymphedema risk in patients undergoing SLN mapping technique are lacking, but scientific societies and organizations are increasingly recognizing its utility and promising studies are ongoing.

To briefly refer to the surgical technique in EC, the GOG LAP-2 study reported that endoscopic surgical staging was associated with fewer postoperative complications (including lymphedema) compared to patients who underwent an open procedure, and this is nowadays the standard of treatment (36). However, in a large series of 1,087 EC patients with severe obesity (Body Mass Index, BMI $\geq 40 \mathrm{~kg} / \mathrm{m}^{2}$ ), no significant differences in the rates of lymphedema were found among minimally invasive robotic, laparoscopic or open surgery (37).

It should be considered that obesity itself (BMI >35 $\mathrm{kg} / \mathrm{m}^{2}$ ) plays a major confounding role because, in several studies, high BMI was an independent prognostic factor for the development of postoperative lymphedema $(11,26,38)$.

Another area of debate about the risk factors for LLL in $\mathrm{EC}$ is the association with postoperative radiotherapy. Some studies have suggested that radiation increases the risk of lymphedema, but most patients in these studies had more than 20 nodes removed, which might increase the risk of lymphedema per se $(39,40)$. In a recent study, the risk of LLL after post-operative radiation (mainly external beam radiation), evaluated through both objective and subjective evaluations, was associated with lymph node positivity $(\mathrm{OR}=3,2 ; 95 \% \mathrm{CI}=1.0007-10 \cdot 7 ; p=0.0499)$ when controlled for lymph-node dissection (41).

We can speculate that, in those patients where there is already an alteration of the lymphatic vessels due to the presence of metastatic or micrometastatic disease, the fibrosis induced by radiotherapy may concur in the alteration of the lymphatic flow, resulting in lymphedema.

Notably, current indications for adjuvant radiotherapy are reserved for intermediate-high risk patients, or for patients with advanced disease (42).

Cervical cancer. Cervical cancer (CC) often affects young women almost always diagnosed at an early stage due to the screening widespread availability in developed countries, but may be diagnosed at an advanced stage in the rest of the world. It is, therefore, important to pay special attention to the impact of treatment complications on the life ahead of these young women.

Radical hysterectomy with pelvic lymph node dissection is the standard treatment for CC in FIGO stage I to stage IIA. The incidence of LLL among the different studies performed on $\mathrm{CC}$ patients undergoing this procedure ranges from $0-55.9 \%(22,40)$
In women with early-stage disease (tumor size $<2 \mathrm{~cm}$ ) who wish to preserve fertility, radical vaginal trachelectomy with pelvic lymphadenectomy appears to be a feasible option (43). Two studies evaluated the incidence of LLL in patients who underwent radical trachelectomy, reporting an incidence of $11 \%$ (44) and $24.1 \%$ (45) respectively (both relying on subjective evaluations). In the study of Frodig et al., women who underwent trachelectomy had persistent LLL comparable to that experienced by patients treated with radical abdominal hysterectomy and significantly higher than those reported by healthy control women $(p=0.031)$ (44). This is not surprising as lymphadenectomy is performed in trachelectomy as well.

Like in EC, post-operative radiotherapy is associated with a higher risk of $\operatorname{LLL}(13,14,15,39,40,46,47,48)$, and the number of removed lymph nodes $(40,49)$ and suprafemoral node dissection seem to be associated with a higher rate of LLL (47).

Studies comparing laparoscopy versus laparotomy are inconsistent: for FIGO stage IA1-IB1, LLL was reported in $3.6 \%$ of cases performed by laparotomy compared to none in the laparoscopy group (22). Conversely, other studies reported no differences between the laparoscopic and the laparotomic lymphadenectomy procedure $(1,44)$. Comparing abdominal radical hysterectomy versus robotic radical hysterectomy, LLL was significantly higher in the laparotomic group (27.5\% vs. 8.3\%, $p=0.001)(50)$.

The SLN biopsy is a promising option in order to minimize LLL in early stage cervical cancer. Many studies have established its feasibility, high detection rates with low false-negative rates, in particular when SLN is detected bilaterally. On the contrary, large tumors $(>2 \mathrm{~cm})$ and lymphovascular space invasion are associated with a higher rate of false-negative results $(9,51)$. However, it is not an accepted standard of treatment as yet.

In advanced locoregional cervical cancer (FIGO stages IIB-IVA), concurrent platin-based chemotherapy and radiation are the standard treatment. Cisplatin also increased radiosensitivity, reducing local recurrences and distant metastases, leading to higher overall and disease-free survival rates (52). Chemotherapy increased fatigue, dyspnea, nausea, vomiting and, especially, the hematologic toxicity, but this effect was generally moderate and reversible with medical treatment. The incidence of late side-effects occurring or persisting more than 60 days after the completion of treatment, like lymphedema, bowel and urinary dysfunction, was similar in patients treated with radiotherapy and chemotherapy or radiotherapy alone (53).

Ovarian cancer. Ovarian cancer (OC) is the leading cause of death among gynecologic malignancies, since diagnosis occurs in more than $75 \%$ of cases at an advanced stage of the disease. 
Complete staging surgery including lymphadenectomy, followed by adjuvant chemotherapy is the standard of care for early-stage disease, while aggressive cytoreductive surgery followed by paclitaxel/platinum-based chemotherapy is the treatment of choice for patients with advanced stage operable disease.

Controversy exists on the role of lymphadenectomy on survival (54). In early stage disease, an RCT showed that systematic lymphadenectomy is mandatory to allow accurate staging of the tumor, but it has no influence on either progression-free survival or overall survival (8). In advanced-stage disease, the therapeutic value of systematic lymphadenectomy is controversial. In a multicenter RCT comparing systematic lymphadenectomy with bulky nodes resection, systematic lymphadenectomy was associated with a significant improvement in progression-free survival, but overall survival was similar in the two arms of treatment (55).

The reported incidence of LLL among OC patients ranges from $4.7 \%$ to $40.8 \%(13,56)$ and most of the studies were performed on heterogeneous cohorts including also patients with CC and EC (1, 13, 14, 34, 39, 40). Only one study specifically addressed OC patients by means of subjective evaluation (56), reporting an incidence of $40.8 \%$ (past $18.3 \%$ and current $22.5 \%$ ); LLL developed in most of the cases $(86.2 \%)$ in the first year after surgery and persisted more than 6 months after treatment in $62.1 \%$ of the women. Interestingly, only half of the patients $(52.1 \%)$ declared to be informed of lymphedema.

As for EC and $\mathrm{CC}$, the most frequently reported risk factors for lymphedema are a high number of removed lymph nodes (40), cellulitis (34) and the removal of circumflex iliac lymph nodes $(34,57)$.

Lymphocele is a frequent condition after lymphadenectomy for OC patients. In a recent study on 800 patients who underwent pelvic and/or paraaortic lymphadenectomy for $\mathrm{EC}, \mathrm{CC}$ or $\mathrm{OC}$, lymphocele was found more frequently among OC patients (occurring in $38.2 \%$ of the 137 OC patients, objective ultrasound evaluation). Furthermore, OC diagnosis was an independent risk factor at multivariate analysis both for lymphocele formation $(\mathrm{OR}=3.137)$ and for being a symptomatic lymphocele $(\mathrm{OR}=2.310)(5)$.

Vulvar cancer. Vulvar cancer is rather uncommon. Treatment relies on surgery including unilateral or bilateral groins dissection for early stage disease and combined therapies for advanced stages. The complications most frequently reported after treatment are wound early breakdown or infection (20-40\%) and permanent lower body lymphedema including most of the cases of genital and mons pubis lymphedema (30-70\%) (23). Many factors possibly associated with lower body lymphedema have been investigated with inconsistent results. Gaarenstroom et al. have shown that lymphedema was frequently associated with the occurrence of early complications; conversely, lymph node metastases, postoperative radiation, age older than 65 years were not significant risk factors for complications and even the separated groin incision was not able to reduce the incidence of lymphedema (58). Conversely, in the study of Gould et al. lower body lymphedema was neither predicted by early complications nor by other factors (use of antibiotics, adjuvant therapy, drainage) (59). The rates of lymphedema were not significantly different according to treatment modalities (single, combination or sequence) in the study of Berger et al. (60). According to some authors preserving the saphenous vein during inguinal lymphadenectomy is associated with a lower risk of lymphedema (61), but this approach is not widely accepted. In an attempt to reduce postoperative complications and lymphedema a study of the topographic distribution of groin lymph nodes on 50 female cadavers demonstrated that a radical deep femoral lymphadenectomy can be obtained without removing the fascia lata because the deep femoral nodes are always located within the opening of the fossa ovalis, and no lymph nodes are distal to the lower margin of the fossa ovalis, under the fascia cribrosa (62).

The SLN biopsy seems to be the most effective strategy aimed at reducing the risk of lower body lymphedema in patients with early-stage vulvar cancer. The GROINS V and the GOG study reported the safety of the SLN biopsy in selected women with vulvar cancer $(23,63)$. In the study of the GOG, women with squamous cell cancer of the vulva were eligible if the depth of invasion was at least $1 \mathrm{~mm}$, the tumor was limited to the vulva, the primary tumor size was at least $2 \mathrm{~cm}$ and not larger than $6 \mathrm{~cm}$ and there were not any groin lymph nodes clinically suspicious for metastases. Women underwent SLN biopsy and inguinal femoral lymphadenectomy, the sensitivity was $91.7 \%$ and the falsenegative rate was $3.7 \%$ (63).

\section{Risk Factors}

Lymphadenectomy is associated with a variable rate of lymphedema depending on many concomitant risk factors regarding the anatomy of the regional lymphatics, the presence of alternate ways of lymphatic drain, the surgical aggressiveness, the number of removed nodes, the removal of specific nodes, the use of adjuvant radiotherapy, the characteristics of the patient (such as BMI, comorbidities and age). Several Authors have analyzed the association between LLL and patient related or treatment related characteristics, in order to define potential risk factors. Table I summarizes the independent risk factors for the development of LLL among gynecologic cancer survivors. 


\section{Treatment}

Although LLL is a long-lasting and debilitating condition, it has not been widely studied in gynecologic cancer patients and, nowadays, there is no consensus about which is the best treatment. On account of its chronic nature, LLL management is lifelong, including conservative, medical and surgical treatments.

Patients should be referred to a specialist as soon as possible to start a treatment, aimed at avoiding, as far as possible, further complications such as limb deformity and skin fibrosis.

The usual management of secondary lymphedema is conservative, reserving operative methods for failed medical therapies (64).

Non-operative management. Combined physical therapy consists of a two steps program carried out by a professional team including particularly trained lymphologists, nurses and physiotherapists. The first step includes skin care to keep it intact, light manual massage to avoid damage to lymphatic vessels, exercise that, increasing muscle mass, stimulates lymph flow and protein absorption and compression with a multi-layered bandage. The second step adds compression with elastic garments and manual lymph drainage when lymphedema worsens.

Drug therapy with diuretics and benzopyrones is helpful, but diuretic agents must be used only for short periods in patients with malignancy as they may cause electrolyte imbalance. Other approaches include intermittent pneumatic compression, thermal therapy, limb elevation, mesotherapy and immunological therapy, but their benefit is unclear $(12,65)$.

Operative management. In gynecologic cancer survivors, surgical treatment is taken into account only when conservative therapy has been unsuccessful. Surgical methods resort to two approaches: physiologic and ablative procedures. Physiologic techniques can only be performed in early stage LLL without severe tissue changes in the affected limb and aim to improve the rate of the lymph flow into the venous circulation. These microsurgery techniques include lymphatic collector implantation, vein and lymph segments transplantation and lymphatic-venous or lymph nodal-venous shunts. This approach has shown long-term results and carries a low rate of complications, but the success rate is highly variable among studies, because of limitations in assessing the volume of the lymphedema, etiology and postoperative management $(12,66)$.

Ablative procedures should be reserved for patients with advanced LLL, fat deposition and tissue fibrosis. They include liposuction, which requires rigorous compliance using compressive garments in the follow-up $(12,67)$ and direct excision, which is helpful but invasive and may cause pain, infections, healing complications, lymphatic fistulas, necrosis of the skin graft and suboptimal cosmetic and functional results (66).

\section{Risk-reducing Strategies}

The shortage of therapeutic strategies must address the attention of the health care providers on preventive techniques, in order to reduce the incidence and severity of lower body lymphedema.

SLN biopsy is a standard procedure for melanoma and breast cancer, reducing surgical times, complications, morbidity and costs. Instead, its application in gynecologic oncology remains still controversial: SLN biopsy is a safe and accepted alternative to inguinal femoral lymphadenectomy in selected women with squamous early-stage $(<4 \mathrm{~cm})$ unifocal vulvar cancer with no suspicious enlarged lymph nodes at imaging (9). Several studies have demonstrated feasibility with high detection rates and low false negative rates in appropriately selected patients with CC or EC (68).

Many authors maintain that removing the circumflex iliac lymph nodes could increase the risk of postoperative symptomatic LLL $(32,57)$. Hareyama et al. compared the incidence of LLL in 2 groups of patients with OC, EC and $\mathrm{CC}$ : in one group circumflex, iliac lymph nodes were removed and in the other circumflex iliac lymph nodes were preserved. The incidence of LLL was significantly lower in the group with preserved nodes; furthermore, no patients in the preserved group had lower extremity cellulitis (34). In addition, circumflex iliac lymph nodes rarely are the regional site of the SLN and the unique metastatic site in early stage gynecologic malignancy (55).

Reducing the use of external beam radiotherapy, that may induce fibrosis preventing lymphatic reconstruction, could reduce the risk of lower body lymphedema; however, the results of the studies are inconsistent.

Some of the risk factors, like BMI, stage of disease, comorbidities can not be modified, but should be carefully investigated and taken into account while planning treatment strategies.

As in breast cancer patients who underwent an axillary dissection, a strong education on the importance of protecting the lower extremity from infection or trauma is of the utmost importance in reducing the risk of post-infectious lymphedema.

\section{Impact on Quality of Life}

Gynaecologic cancer patients often experience a low QoL due to cancer treatments, with long-term troubles regarding sexuality, bladder and bowel functions (69). They often report symptoms such as pain, diarrhea and lymphedema 
Table I. Independent Risk Factors for the development of lower-limb lymphedema. A: In endometrial cancer patients, B: in cervical cancer patients, $C$ : in endometrial, cervical and ovarian cancer patients. NSAID: non-steroidal anti-inflammatory drugs; BMI: body mass index.

\section{A-ENDOMETRIAL CANCER}

\begin{tabular}{lccc}
\hline Indipendent Risk Factor & Adjusted Odds Ratio $(95 \% \mathrm{CI})$ & $p$-Value & Authors \\
\hline Pre-cancer NSAID use & $1.7(1.1-2.8)$ & 0.029 & Beesley VL, Rowlands IJ, Hayes SC, et al. 2015 (32) \\
BMI at time of surgery WHO class III & $4.69(2.71,8.13)$ & 0.001 & Yost KJ, Cheville AL, Al-Hilli MM, et al. 2014 (26) \\
Congestive heart failure & $2.58(1.23,5.40)$ & 0.1 & Yost KJ, Cheville AL, Al-Hilli MM, et al. 2014 (26) \\
Lymphadenectomy & $2.04(1.39,2.99)$ & $<0.001$ & Yost KJ, Cheville AL, Al-Hilli MM, et al. 2014 (26) \\
Number of removed lymph nodes & $18.6(10.3-33.5)$ & $<0.001$ & Beesley VL, Rowlands IJ, Hayes SC, et al. 2015 (32) \\
$\quad \begin{array}{l}\geq 15 \\
\geq 31\end{array}$ & $2.6(1.4-4.8)$ & 0.003 & Todo Y, Yamamoto R, Minobe S, et al. 2010 (33) \\
Removal of circumflex iliac lymph nodes & $6.1(1.3-28.5)$ & 0.02 & Todo Y, Yamamoto R, Minobe S, et al. 2010 (33) \\
Adjuvant chemotherapy & $1.7(1.1-2.8)$ & 0.031 & Beesley VL, Rowlands IJ, Hayes SC, et al. 2015 (32) \\
External beam radiation therapy & $3.00(1.46,6.16)$ & 0.003 & Yost KJ, Cheville AL, Al-Hilli MM, et al. 2014 (26) \\
Adjuvant radiotherapy & $5.3(2.2-13.1)$ & 0.0003 & Todo Y, Yamamoto R, Minobe S, et al. 2010 (33) \\
\hline
\end{tabular}

\section{B-CERVICAL CANCER}

\begin{tabular}{lccc}
\hline Indipendent Risk Factor & Adjusted Odds Ratio (95\%CI) & $p$-Value & Authors \\
\hline Adjuvant radiotherapy & $3.47(2.08-5.78)$ & $<0.0001$ & Kim JH, Choi JH, Ki EY, et al. 2012 (15) \\
Suprafemoral node dissection & $3.7(1.2-10.9)$ & 0.019 & Ohba Y, Todo Y, Kobayashi N, et al. 2011(47) \\
& $9.5(1.2-73.3)$ & 0.031 & Ohba Y, Todo Y, Kobayashi N, et al. 2011(47) \\
\hline
\end{tabular}

\section{C-ENDOMETRIAL, CERVICAL and OVARIAN CANCER}

\begin{tabular}{lccc}
\hline Indipendent Risk Factor & Adjusted Odds Ratio (95\% IC) & $p$-Value & Authors \\
\hline Adjuvant radiotherapy & $1.79(1.20-2.67)$ & 0.006 & Tada H, Teramukai S, Fukushima M, et al. 2009 (39) \\
Removal of circumflex iliac lymph nodes & $4.28(2.09-8.77)$ & $<0.0001$ & Hareyama H, Hada K, Goto K, et al. 2015 (4) \\
Cellulitis & $3.48(2.03-5.98)$ & $<0.0001$ & Hareyama H, Hada K, Goto K, et al. 2015 (4) \\
Number of removed lymph nodes & $0.99(0.98-0.99)$ & 0.038 & Hareyama H, Hada K, Goto K, et al. 2015 (4) \\
\hline
\end{tabular}

(70). LLL deeply impacts physical activity $(71,72)$ and normal activities like walking, standing or house working. Financial difficulties are also reported $(72,73)$ because of the additional costs due to rehabilitation treatments (74), changes of clothing to hide the appearance of swollen legs or the compression garments (75) or to the inability to continue the employment $(73,75)$. Furthermore, women with LLL are more likely to experience symptoms of depression or anxiety $(72,76)$, be less satisfied with sleep $(71,72)$, more worried about a recurrence of cancer and more likely to interpret symptoms as possible indicators of recurrence (71). Lymphedema-induced psychological distress and the limitation in normal movements can determine social isolation $(71,72,75)$ and loss of intimacy with the partner (75). In the study of Ryan et al. the discovery of LLL was described as a shock and women reported to feel alone and betrayed (75).

Gynecologic cancer survivors with lymphedema have higher supportive care needs in the domains of information and symptom management as compared with those who had no swelling (13); however, they are less likely to use supportive care services (76).

Dissatisfaction is reported concerning the poor knowledge about lymphedema and its management among healthcare professionals (75). Many patients complain of a considerable delay in finding appropriate information and treatment (76) and of not being informed about lymphedema risk until they were diagnosed (13).

Educating healthcare professionals and women is crucial in order to detect early signals and help patients to access the appropriate care. Information to the patients should be given both orally and in a written format, preoperatively and before discharge from the hospital. Teaching nurses about LLL is important since they can discuss the problem with women, explaining how to maintain skin integrity avoiding trauma or infection (58). The collaboration with a lymphedema therapist and working in a multidisciplinary team are needed in order to manage patients with lymphedema. 


\section{Conclusion}

Lower body lymphedema following gynecologic cancer treatment is a chronic condition poorly responding to any treatment efforts, that strongly impacts QoL; special attention must be paid in order to minimize its impact.

There is no consensus about a uniform diagnostic evaluation and, consequently, the reported incidence of secondary lymphedema varies among different studies. The true prevalence of the condition is unknown, as well as the proper management once it has been diagnosed.

Lymphadenectomy remains the principal cause of LLL and its adverse effects can be worsened by the other known risk factors.

Data about the therapeutic role of lymphadenectomy in gynecologic malignancies are still inconclusive and the incidence and persistence of complications are well established, therefore an evidence-based selection of the patients that could benefit from lymphadenectomy is strongly advocated. Surgical treatment is luckily moving towards less invasive approaches. The reduction of the indications to extensive lymphadenectomy and the increasing use of SLN biopsy technique are both promising steps in this direction.

Further studies, in particular prospective multicenter RCTs, are needed to better elucidate the etiology, patogenesis, diagnosis and treatment of lymphedema in gynecologic cancer survivors. Special attention should be devoted to stratify patients by type of cancer, surgical approach, type of adjuvant treatment and stage of the disease. Standardization in lymphedema evaluation is required to compare the outcome of different treatments. The ongoing Gynecologic Oncology Group LEG study (GOG 244, The Lymphedema and Gynecologic Cancer Study, NCT00956670) will help on that, providing critical information on incidence and risk factors for lymphedema in all gynecologic cancer patients.

Awareness about lymphedema must be encouraged both in patients and health care providers, with the goal of avoiding unnecessary procedures that may increase its risk and make both actors ready to recognize it and treat it promptly when it occurs.

\section{Conflicts of Interest}

All Authors disclaim any financial and personal relationships with other people or organizations that could inappropriately influence their work.

\section{Acknowledgements}

The Authors would like to thank Prof. Piero Sismondi for revising the manuscript and Dr. Franco Nessi for his assistance with vascular surgery issues.

\section{References}

1 Achouri A, Huchon C, Bats AS, Bensaid C, Nos C and Lécuru F: Complications of lymphadenectomy for gynecologic cancer. EJSO 39: 81-86, 2013.

2 Emons G: Significance of Lymph Node Dissection in Gynecological Oncology. Oncol Res Treat 37: 500-504, 2014.

3 Lockwood-Rayermann S: Lymphedema in Gynecologic Cancer Survivors. An Area for Exploration? Cancer Nurs 30: E11-18, 2007.

4 Hareyama H, Hada K and Goto K: Prevalence, Classification, and Risk Factors for Postoperative Lower Extremity Lymphedema in Women With Gynecologic Malignancies A Retrospective Study. Int J Gynecol Cancer 25: 751-757, 2015.

5 Zikan M, Fischerova D, Pikakova I, Slama J, Weinberger V, Dusek L and Cibula D: A prospective study examining the incidence of asymptomatic and symptomatic lymphoceles following lymphadenectomy in patients with gynecological cancer. Gynecol Oncol 137: 291-298, 2015.

6 ASTEC study group, Kitchener H, Swart AM, Qian Q, Amos C and Parmar MK: Efficacy of systematic pelvic lymphadenectomy in endometrial cancer (MRC ASTEC trial): a randomised study. Lancet 373: 125-136, 2009.

7 Benedetti Panici P, Basile S and Maneschi F: Systematic pelvic lymphadenectomy vs. no lymphadenectomy in early-stage endometrial carcinoma: randomized clinical trial. J Natl Cancer Inst 100: 1707-1716, 2008.

8 Maggioni A, Benedetti Panici P, Dell'Anna T, Landoni F, Lissoni A, Pellegrino A, Rossi RS, Chiari S, Campagnutta E, Greggi S, Angioli R, Manci N, Calcagno M, Scambia G, Fossati R, Floriani I, Torri V, Grassi R and Mangioni C: Randomised study of systematic lymphadenectomy in patients with epithelial ovarian cancer macroscopically confined to the pelvis. $\mathrm{Br} \mathrm{J}$ Cancer 95: 699-704, 2006.

9 Cibula D, Oonk MH and Abu-Rustum NR: Sentinel lymph node biopsy in the management of gynecologic cancer. Gynecol Oncol 136(1): 54-59, 2015.

10 Benito V, Romeu S, Esparza M, Carballo S, Arencibia O, Medina N and Lubrano A: Safety and Feasibility Analysis of Laparoscopic Lymphadenectomy in Pelvic Gynecologic Malignancies. A Prospective Study. Int J Gynecol Cancer 25: 1704-1710, 2015.

11 Mendivil AA, Rettenmaier MA, Abaid LN, Brown JV, Micha JP, Lopez KL and Goldstein BH: Lower-extremity lymphedema following management for endometrial and cervical cancer. Surg Oncol 25: 200-204, 2016.

12 International Society of Lymphology: The diagnosis and treatment of peripheral lymphedema: 2013 Consensus Document of the International Society of Lymphology. Lymphology 46: 1$11,2013$.

13 Beesley V, Janda M, Eakin E, Obermair A and Battistutta D: Lymphedema after gynecological cancer treatment: prevalence, correlates, and supportive care needs. Cancer 109: 2607-2614, 2007.

14 Ryan M, Stainton MC, Slaytor EK, Jaconelli C, Watts S and Mackenzie P: Aetiology and prevalence of lower limb lymphoedema following treatment for gynaecological cancer. Aust N Z J Obstet Gynaecol 43: 148-151, 2003.

15 Kim JH, Choi JH, Ki EY, Lee SJ, Yoon JH, Lee KH, Park TC, Park JS, Bae SN and Hur SY: Incidence and Risk Factors of Lower-Extremity Lymphedema After Radical Surgery With or 
Without Adjuvant Radiotherapy in Patients With FIGO Stage I to Stage IIA Cervical Cancer. Int J Gynecol Cancer 22: 686-691, 2012.

16 Brown J: A clinically useful method for evaluating lymphedema. Clin J Oncol Nurs 8: 35-38, 2004.

17 Deltombe T, Jamart J, Recloux S, Legrand C, Vandenbroeck N, Theys S and Hanson P: Reliability and limits of agreement of circumferential water displacement and optoelectronic volumetry in the measurement of upper limb lymphedema. Lymphology 40: 26-34, 2007.

18 Liu N, Wang C and Sun M: Noncontrast three-dimensional magnetic resonance imaging $v s$. lymphoscintigraphy in the evaluation of lymph circulation disorders: a comparative study. J Vasc Surg 41: 69-75, 2005.

19 Suehiro K, Morikage N, Murakami M, Yamashita O, Samura M and Hamano K: Significance of ultrasound examination of skin and subcutaneous tissue in secondary lower extremity lymphedema. Ann Vasc Dis 6: 180-188, 2013.

20 Aaronson NK, Ahmedzai S, Bergman B, Bullinger M, Cull A, Duez NJ, Filiberti A, Flechtner H, Fleishman SB, de Haes JC, Kaasa S, Klee M, Osoba D, Razavi D, Rofe PB, Schraub S, Sneeuw K, Sullivan $M$ and Takeda F: The European Organization for Research and Treatment of Cancer QLQ-C30: a quality-of-life instrument for use in international clinical trials in oncology. J Natl Cancer Inst 85: 365-337, 1993.

21 Carter J, Raviv L, Appollo K, Baser RE, Iasonos A and Barakat RR: A pilot study using the Gynecologic Cancer Lymphedema Questionnaire (GCLQ) as a clinical care tool to identify lower extremity lymphedema in gynecologic cancer survivors. Gynecol Oncol 117: 317-323, 2010.

22 Abu-Rustum NR, Gemignani ML, Moore K, Sonoda Y, Venkatraman E, Brown C, Poynor E, Chi DS and Barakat RR: Total laparoscopic radical hysterectomy with pelvic lymphadenectomy using the argon-beam coagulator: pilot data and comparison to laparotomy. Gynecol Oncol 91: 402-409, 2003.

23 Van der Zee AG, Oonk MH, De Hullu JA, Ansink AC, Vergote I, Verheijen RH, Maggioni A, Gaarenstroom KN, Baldwin PJ, Van Dorst EB, Van der Velden J, Hermans RH, van der Putten H, Drouin P, Schneider A and Sluiter WJ: Sentinel node dissection is safe in the treatment of early-stage vulvar cancer. J Clin Oncol 26: 884-889, 2008.

24 Miller KD, Siegel RL, Lin CC, Mariotto AB, Kramer JL, Rowland $\mathrm{JH}$, Stein KD, Alteri R and Jemal A: Cancer treatment and survivorship statistics, 2016. CA Cancer J Clin 66: 271-289, 2016.

25 Abu-Rustum NR, Alektiar K, Iasonos A, Lev G, Sonoda Y, Aghajanian C, Chi DS and Barakat RR: The incidence of symptomatic lower-extremity lymphedema following treatment of uterine corpus malignancies: a 12-year experience at Memorial Sloan-Kettering Cancer Center. Gynecol Oncol 103: 714-718, 2006.

26 Yost KJ, Cheville AL, Al-Hilli MM, Mariani A, Barrette BA, McGree ME, Weaver AL and Dowdy SC: Lymphedema after surgery for endometrial cancer: prevalence, risk factors, and quality of life. Obstet Gynecol 124: 307-315, 2014.

27 van de Poll-Franse LV, Pijnenborg JM, Boll D, Vos MC, van den Berg H, Lybeert ML, de Winter K and Kruitwagen RF: Health related quality of life and symptoms after pelvic lymphadenectomy or radiotherapy $v s$. no adjuvant regional treatment in early-stage endometrial carcinoma: a large population-based study. Gynecol Oncol 127: 153-160, 2012.
28 Frost JA, Webster KE, Bryant A and Morrison J: Lymphadenectomy for the management of endometrial cancer. Cochrane Database Syst Rev 9: CD007585, 2015.

29 Kilgore LC, Partridge EE, Alvarez RD, Austin JM, Shingleton HM, Noojin F 3rd and Conner W: Adenocarcinoma of the endometrium: survival comparisons of patients with and without pelvic node sampling. Gynecol Oncol 56: 29-33, 1995.

30 AlHilli MM, Podratz KC, Dowdy SC, Bakkum-Gamez JN, Weaver AL, McGree ME, Kumar S, Keeney GL, Cliby WA and Mariani A: Preoperative biopsy and intraoperative tumor diameter predict lymph node dissemination in endometrial cancer. Gynecol Oncol 128: 294-299, 2013.

31 Yanazume S, Saito T, Eto T, Yamanaka T, Nishiyama K, Okadome $\mathrm{M}$ and Ariyoshi K: Reassessment of the utility of frozen sections in endometrial cancer surgery using tumor diameter as an additional factor. Am J Obstet Gynecol 204: 531e1-7, 2011.

32 Beesley VL, Rowlands IJ, Hayes SC, Janda M, O'Rourke P, Marquart L, Quinn MA, Spurdle AB, Obermair A, Brand A, Oehler MK, Leung Y, McQuire L and Webb PM; Australian National Endometrial Cancer Study Group: Incidence, risk factors and estimates of a woman's risk of developing secondary lower limb lymphedema and lymphedema-specific supportive care needs in women treated for endometrial cancer. Gynecol Oncol 136: 87-93, 2015.

33 Todo Y, Yamamoto R, Minobe S, Suzuki Y, Takeshi U, Nakatani M, Aoyagi Y, Ohba Y, Okamoto K and Kato H: Risk factors for postoperative lower-extremity lymphedema in endometrial cancer survivors who had treatment including lymphadenectomy. Gynecol Oncol 119: 60-64, 2010.

34 Hareyama H, Ito K, Hada K, Uchida A, Hayakashi Y, Hirayama E, Oikawa M and Okuyama K: Reduction/prevention of lower extremity lymphedema after pelvic and para-aortic lymphadenectomy for patients with gynecologic malignancies. Ann Surg Oncol 19: 268-273, 2012.

35 Smith AJB, Fader AN and Tanner EJ: Sentinel Lymph Node Assessment in Endometrial Cancer: A Systematic Review and Meta-analysis, American Journal of Obstetrics and Gynecology 216: 459-476, 2017.

36 Walker JL, Piedmonte MR, Spirtos NM, Eisenkop SM, Schlaerth JB, Mannel RS, Spiegel G, Barakat R, Pearl ML and Sharma SK: Laparoscopy compared with laparotomy for comprehensive surgical staging of uterine cancer: Gynecologic Oncology Group Study LAP2. J Clin Oncol 27: 5331-5336, 2009.

37 Chan JK, Gardner AB, Taylor K, Thompson CA, Blansit K, Yu $\mathrm{X}$ and Kapp DS: Robotic versus laparoscopic versus open surgery in morbidly obese endometrial cancer patients - a comparative analysis of total charges and complication rates. Gynecol Oncol 139: 300-305, 2015.

38 Nicholas Z, Hu N, Ying J, Soisson P, Dodson M and Gaffney DK: Impact of comorbid conditions on survival in endometrial cancer. Am J Clin Oncol 37: 131-134, 2014.

39 Tada H, Teramukai S, Fukushima M and Sasaki H: Risk factors for lower limb lymphedema after lymph node dissection in patients with ovarian and uterine carcinoma. BMC Cancer 9: 47, 2009.

40 Biglia N, Librino A, Ottino MC, Panuccio E, Daniele A and Chahin A: Lower limb lymphedema and neurological complications after lymphadenectomy for gynecological cancer. Int J Gynecol Cancer 25: 521-525, 2015. 
41 Mitra D, Catalano PJ, Cimbak N, Damato AL, Muto MG and Viswanathan AN: The risk of lymphedema after postoperative radiation therapy in endometrial cancer. J Gynecol Oncol 27: e4, 2016.

42 Colombo N, Creutzberg C, Amant F, Bosse T, González-Martín A, Ledermann J, Marth C, Nout R, Querleu D, Mirza MR and Sessa C and ESMO-ESGO-ESTRO Endometrial Consensus Conference Working Group: ESMO-ESGO-ESTRO Consensus Conference on Endometrial Cancer: diagnosis, treatment and follow-up. Ann Oncol 27: 16-41, 2016.

43 Schneider A, Erdemoglu E, Chiantera V, Reed N, Morice P, Rodolakis A, Denschlag D and Kesic V: Clinical recommendation radical trachelectomy for fertility preservation in patients with early-stage cervical cancer. Int J Gynecol Cancer 22: 659-666, 2012.

44 Frøding LP, Ottosen C, Mosgaard BJ and Jensen PT: Quality of life, urogynecological morbidity, and lymphedema after radical vaginal trachelectomy for early-stage cervical cancer. Int J Gynecol Cancer 25: 699-670, 2015.

45 Lanowska M, Mangler M, Spek A, Grittner U, Hasenbein K, Chiantera V, Hertel H, Schneider A, Köhler C and Speiser D: Radical vaginal trachelectomy (RVT) combined with laparoscopic lymphadenectomy: prospective study of 225 patients with early-stage cervical cancer. Int J Gynecol Cancer 21: 1458-1464, 2011.

46 Nakamura K, Kitahara Y, Satoh T, Takei Y, Takano M, Nagao S, Sekiguchi I and Suzuki M: Analysis of the effect of adjuvant radiotherapy on outcomes and complications after radical hysterectomy in FIGO stage IB1 cervical cancer patients with intermediate risk factors (GOTIC Study). World J Surg Oncol 14: 173, 2016.

47 Ohba Y, Todo Y, Kobayashi N, Kaneuchi M, Watari H, Takeda M, Sudo S, Kudo M, Kato H and Sakuragi N: Risk factors for lower-limb lymphedema after surgery for cervical cancer. Int J Clin Oncol 16: 238-243, 2011.

48 Hosaka M, Watari H, Takeda M, Moriwaki M, Hara Y, Todo Y, Ebina $\mathrm{Y}$ and Sakuragi N: Treatment of cervical cancer with adjuvant chemotherapy versus adjuvant radiotherapy after radical hysterectomy and systematic lymphadenectomy. J Obstet Gynaecol Res 34: 552-556, 2008.

49 Füller J, Guderian D, Köhler C, Achim Schneider A and Wendt TG: Lymphedema of the lower extremities after lymphadenectomy and radiotherapy for cervical cancer. Strahlenther Onkol 184: 206211,2008

50 Zanagnolo V, Minig L, Rollo D, Tomaselli T, Aletti G, Bocciolone L, Landoni F, Cardenas Rebollo JM and Maggioni A: Clinical and oncologic outcomes of robotic versus abdominal radical hysterectomy for women with cervical cancer. Experience at a referral cancer center. Int J Gynecol Cancer 26: 568-574, 2016

51 Lécuru F, Mathevet P, Querleu D, Leblanc E, Morice P, Daraï E, Marret H, Magaud L, Gillaizeau F, Chatellier G and Dargent D: Bilateral negative sentinel nodes accurately predict absence of lymph node metastasis in early cervical cancer: results of the SENTICOL study. J Clin Oncol 29: 1686-1891, 2011.

52 Chemoradiotherapy for Cervical Cancer Meta-analysis Collaboration (CCCMAC): Reducing uncertainties about the effects of chemoradiotherapy for cervical cancer: individual patient data meta-analysis. Cochrane Database Syst Rev 1: CD008285, 2010
53 Morris M, Eifel PJ, Lu J, Grigsby PW, Levenback C, Stevens RE, Rotman M, Gershenson DM and Mutch DG: Pelvic radiation with concurrent chemotherapy compared with pelvic and para-aortic radiation for high-risk cervical cancer. $\mathrm{N}$ Engl $\mathrm{J}$ Med 340: 1137-1143, 1999.

54 Mikami M: Role of lymphadenectomy for ovarian cancer. J Gynecol Oncol 25: 279-281, 2014.

55 Panici PB, Maggioni A, Hacker N, Landoni F, Ackermann S, Campagnutta E, Tamussino K, Winter R, Pellegrino A, Greggi S, Angioli R, Manci N, Scambia G, Dell'Anna T, Fossati R, Floriani I, Rossi RS, Grassi R, Favalli G, Raspagliesi F, Giannarelli D, Martella L and Mangioni C: Systematic aortic and pelvic lymphadenectomy versus resection of bulky nodes only in optimally debulked advanced ovarian cancer: a randomized clinical trial. J Natl Cancer Inst 97: 560-566, 2005.

56 Lim MC, Lee JS, Nam BH, Seo SS, Kang S and Park SY: Lower extremity edema in patients with early ovarian cancer. J Ovarian Res 7: 28, 2014.

57 Abu-Rustum NR and Barakat RR: Observation on the role of circumflex iliac node resection and etiology of lower extremity lymphedema following pelvic lymphadenectomy for gynecologic malignancy. Gynecol Oncol 106: 4-5, 2007.

58 Gaarenstroom KN, Kenter GG, Trimbos JB, Agous I, Amant F, Peters AA and Vergote I: Postoperative complications after vulvectomy and inguinofemoral lymphadenectomy using separate groin incisions. Int J Gynecol Cancer 13: 522-527, 2003.

59 Gould N, Kamelle S, Tillmanns T, Scribner D, Gold M, Walker $\mathrm{J}$ and Mannel R: Predictors of complications after inguinal lymphadenectomy. Gynecol Oncol 82: 329-332, 2001.

60 Berger J, Scott E, Sukumvanich P, Smith A, Olawaiye A, Comerci J, Kelley JL, Beriwal S and Huang M: The effect of groin treatment modality and sequence on clinically significant chronic lymphedema in patients with vulvar carcinoma. Int $\mathbf{J}$ Gynecol Cancer 25: 119-124, 2015.

61 Zhang SH, Sood AK, Sorosky JI, Anderson B and Buller RE: Preservation of the saphenous vein during inguinal lymphadenectomy decreases morbidity in patients with carcinoma of the vulva. Cancer 89: 1520-1525, 2000.

62 Borgno G, Micheletti L, Barbero M, Cavanna L, Preti M, Valentino MC, Ghiringhello B and Bocci A: Topographic distribution of groin lymph nodes. A study of 50 female cadavers. J Reprod Med 35: 1127-1129, 1990.

63 Levenback CF, Ali S, Coleman RL, Gold MA, Fowler JM, Judson PL, Bell MC, De Geest K, Spirtos NM, Potkul RK, Leitao MM Jr, Bakkum-Gamez JN, Rossi EC, Lentz SS, Burke JJ 2nd, Van Le L and Trimble CL: Lymphatic mapping and sentinel lymph node biopsy in women with squamous cell carcinoma of the vulva: a gynecologic oncology group study. $\mathrm{J}$ Clin Oncol 30: 3786-3791, 2012.

64 Douglass J, Graves P and Gordon S: Self-care for management of secondary lymphedema: a systematic review. PLoS Negl Trop Dis 10: e0004740, 2016.

65 Korpan MI, Crevenna R and Fialka-Moser V: Lymphedema: a therapeutic approach in the treatment and rehabilitation of cancer patients. Am J Phys Med Rehabil 90: 69-75, 2011.

66 Basta MN, Gao LL and Wu LC: Operative treatment of peripheral lymphedema: a systematic meta-analysis of the efficacy and safety of lymphovenous microsurgery and tissue transplantation. Plast Reconstr Surg 133: 905-913, 2014. 
67 Brorson H, Ohlin K, Olsson G, Svensson B and Svensson H: Controlled compression and liposuction treatment for lowerextremity lymphedema. Lymphology 41: 52-63, 2008.

68 Smith B and Backes F: The Role of Sentinel Lymph Nodes in Endometrial and Cervical Cancer. J Surg Oncol 112: 753-760, 2015.

69 Gargiulo P, Arenare L, Pisano C, Cecere SC, Falivene S, Greggi S, Tambaro R, Facchini G, De Palma G, Scaffa C, Della Pepa C, Pignata $S$ and Di Napoli M: Long-term toxicity and quality of life in patients treated for locally advanced cervical cancer. Oncology 90: 29-35, 2016.

70 Karabuga H, Gultekin M, Tulunay G, Yuce K, Ayhan A, Yuce D and Yildiz F: Assessing the quality of life in patients with endometrial cancer treated with adjuvant radiotherapy. Int $\mathrm{J}$ Gynecol Cancer 25: 1526-1533, 2015.

71 Dunberger G, Helene Lindquist E, Waldenström AC, Nyberg T, Steineck G and Åvall-Lundqvist E: Lower limb lymphedema in gynecological cancer survivors - effect on daily life functioning. Support Care Cancer 21: 3063-3070, 2013.

72 de Melo Ferreira AP, de Figueiredo EM, Lima RA, Cândido EB, de Castro Monteiro MV, de Figueiredo Franco TM, Traiman P and da Silva-Filho AL: Quality of life in women with vulvar cancer submitted to surgical treatment: a comparative study. Eur J Obstet Gynecol Reprod Biol 165: 91-95, 2012.
73 Kim SI, Lim MC, Lee JS, Lee Y, Park K, Joo J, Seo SS, Kang S, Chung SH and Park SY: Impact of lower limb lymphedema on quality of life in gynecologic cancer survivors after pelvic lymph node dissection. Eur J Obstet Gynecol Reprod Biol 192: 31-36, 2015.

74 Finnane A, Hayes SC, Obermair A and Janda M: Quality of life of women with lower-limb lymphedema following gynecological cancer. Expert Rev Pharmacoecon Outcomes Res 11: 287-297, 2011.

75 Ryan M, Stainton MC, Jaconelli C, Watts S, MacKenzie P and Mansber T: The experience of lower limb lymphedema for women after treatment for gynecologic cancer. Oncol Nurs Forum 30: 417-423, 2003.

76 Kusters I, Williams M, Obermair A and Janda M: Women with self-reported lower-limb lymphedema after treatment for gynecological cancers: are they more likely to self-report psychosocial symptoms and less likely to use services? J Community Support Oncol 13: 55-61, 2015.

Received May 26, 2017

Revised June 14, 2017

Accepted June 19, 2017 